\title{
Percepção do envolvimento parental e o desempenho escolar de crianças do Ensino Fundamental I
}

\section{Parental involvement and the academic performance of elementary school children}

\author{
Júlio Antônio Moreira Gomes ${ }^{1}$, Neide de Brito Cunha²
}

Resumo

Considerando o envolvimento da família na aprendizagem escolar, o objetivo principal deste estudo é o de verificar se há relação entre o envolvimento parental e o desempenho escolar das crianças. Tem ainda, como objetivos secundários, comparar as médias obtidas por escola, por ano escolar, por idade e por sexo. Participaram 112 alunos do Ensino Fundamental I, ambos os sexos, com idades de 8 a 12 anos, do $3^{\circ}$ ao $5^{\circ}$ ano, de duas escolas públicas de Minas Gerais. Os participantes responderam dois questionários "Questionário sobre avaliação do relacionamento com o pai, na visão dos filhos" e com a mãe, na visão dos filhos. O desempenho escolar foi levantado nas escolas por meio de suas notas nas secretarias das instituições. Os resultados mostraram que somente em relação ao sexo das crianças houve diferenças estatisticamente significativas. Não foram encontradas correlações entre as médias da avaliação do relacionamento com os pais e o desempenho escolar. Esse resultado pode ser o reflexo de que as famílias e a escola não têm agido em conjunto, pela percepção das crianças.

Palavras-chave: Desempenho escolar. Envolvimento parental. Ensino fundamental.

\begin{abstract}
Considering family involvement in school learning, the main objective of this study is to verify the relationship between parental involvement and children's school performance. It also has, as specific objectives, to compare the averages obtained by school, by school year, by age and by sex. A total of 112 primary school children of both sexes, aged 8 to 12 years old, from the 3 rd to the 5 th grade, participated in two public schools in Minas Gerais-Brazil. The children answered two questionnaires "Questionnaire on evaluation of the relationship with the father in the eyes of the children" and with the mother, in the view of the children. Academic performance was raised in schools through their grades in the secretariats of the institutions. The results showed that only in the sex of the children there were statistically significant differences. No correlations were found between the means of the evaluation of the relationship with the parents and the academic performance. This result may reflect the fact that families and schools have not acted together, as perceived by children.
\end{abstract}

Keywords: Academic performance. Parental involvement. Elementary school.

1 Mestre em Educação pela Universidade do Vale do Sapucaí.

2 Pós-doutorado em Educação pela Universidade Estadual de Campinas. Docente Permanente do Mestrado em Educação da Universidade do Vale do Sapucaí. E-mail: neidedebritocunha@gmail.com 


\section{Introdução}

As crianças aprendem a conduta habitual da sociedade, a forma de interpretar o mundo e de atuar, em situações também habituais, com adultos próximos e em amplos espaços de tempo. As mudanças observadas durante a infância não podem ser entendidas à margem das aprendizagens e das relações que são realizadas e estabelecidas, nessa época, tanto no contexto familiar, na escola e em outros âmbitos (BRONFENBRENNER, 2002).

Os pais e a família têm um papel importante na aprendizagem escolar das crianças. Guidetti et al. (2010) destacam que, dentre os vários aspectos do ambiente familiar que proporcionam o relacionamento com a vida escolar infantil, destacase o ambiente familiar. Os autores ressaltam, ainda, a organização e a supervisão dos pais nas rotinas infantis e as chances de interação com os pais.

Smith e Strick (2012) defendem que as dificuldades de aprendizagem podem ser causadas por problemas intrínsecos ao aluno, como problemas cognitivos, porém a extensão em que esse aluno é afetado, por estas dificuldades, está condicionada ao ambiente em que vive, ou seja, extrínseco ao aluno. Assim, os contextos familiares, escolares e sociais podem afetar sobremaneira os problemas, de forma a agravá-los ou diminuí-los.

A família é influenciada pelas transformações sociais, culturais e financeiras. Em função disso, os pais ou responsáveis vão se adaptando em sua maneira de estabelecer as interações e relacionamentos entre seus membros. A relação estabelecida entre a família e a escola, entendida como uma parceria firmada com potencial para ajudar positivamente na escolaridade de seus filhos é definida como envolvimento parental por Christovam e Cia (2013). O termo parental é utilizado para se referir a toda e qualquer pessoa do núcleo familiar do aluno que participe da vida escolar da criança.

Borsa e Nunes (2011), considerando a ênfase atribuída pela sociedade ao papel da mãe na família nuclear, em comparação com o papel do pai, realizaram uma discussão acerca dos aspectos psicossociais da parentalidade por meio de um levantamento de artigos científicos sobre maternidade e paternidade em diferentes bases de dados online, com o objetivo de verificar a frequência de estudos publicados. Os resultados corroboraram a expectativa de que os estudos sobre a relação mãe/filhos(as) foram mais abundantes que os estudos sobre pais/filhos(as), reforçando a ideia construída socialmente de que as crianças devem ser cuidadas pelas mães, prioritariamente. Segundo os autores, a concepção, construída ao longo da história, acaba por diferenciar o papel de homens e mulheres na família e a maneira com que pais e mães se relacionam com suas crianças. Os autores salientaram o fato de que, a despeito das diversas mudanças ocorridas nos papéis sociais e na dinâmica das famílias contemporâneas, as mulheres ainda são vistas como as principais cuidadoras, sendo atribuído a elas o cuidado prioritário não apenas dos filhos, mas também do lar.

Dentro do contexto social em que vivem as famílias, como uma instituição social, Cia e Barham (2009) afirmam que o divórcio e a separação dos pais são fatores de riscos para as crianças que podem trazer queda na qualidade da interação entre o principal responsável ou cuidador, normalmente a mãe, e as crianças. De um lado, o contexto monoparental pode diminuir o espaço de tempo que o cuidador principal tem para influenciar o desenvolvimento da relação com seus filhos. De outro lado, pode ser que o cuidador passe a ter mais a colaboração de seus filhos do que em famílias do tipo biparental, criando uma interdependência e ainda um elevado senso de responsabilidade entre essas crianças, que pode aproximar e fortalecer essa relação.

Martinelli (2002) destaca que um fator a ser observado no processo de aprendizagem é o aspecto afetivo. Segundo a autora, situações como o abandono ou descaso com a criança, a separação litigiosa ou não dos pais, a falta de um deles, por 
morte, um ambiente contraditório da manifestação afetiva de atenção e a depreciação infantil interferem negativamente no processo de aprendizagem das crianças. Cia e Barham (2009) acrescentam que o baixo envolvimento do pai ou sua total ausência é um fator de risco ao desenvolvimento das crianças porque o envolvimento da pessoa do pai afeta o compromisso dos seus filhos nos estudos, impactando no seu desempenho escolar.

No entanto, mesmo sendo de caráter imprescindível, a participação da família no processo de aprendizagem, normalmente é ignorada no seu papel importante no apoio a seus filhos na solução dos desafios e atividades escolares. Dessa maneira, pode-se observar que várias circunstâncias do ambiente familiar se relacionam com a vida escolar infantil, pontualmente com o desempenho escolar infantil (GUIDETTI et al., 2010).

Lima e Machado (2012) exemplificam que a aprendizagem da criança está associada ao acompanhamento familiar. As escolas costumam vincular esse apoio sobretudo à supervisão das tarefas de casa. Nesse sentido, a tarefa surge como um índice avaliador da participação e envolvimento efetivo da família no processo de ensino e aprendizagem. A realização das atividades propostas para o lar é uma manifestação apropriada do acompanhamento familiar, este indicador aponta que a família está dando o suporte necessário para que o aluno apresente um reforço domiciliar e com isto facilite a sua aprendizagem.

Casarin Ramos (2007) menciona que, durante a formação da criança, é necessário que todos aqueles que exercem influência sobre ela trabalhem juntos. Esse trabalho em conjunto ajuda em um crescimento intelectual coordenado, sem conflitos entre escola e pais. Quando os pais participam da vida escolar do filho, constroem um indivíduo mais capacitado para a vida em sociedade.

Dada a importância dessa relação, o Programa Erasmus + da Comissão Europeia teve início em setembro de 2015, com o objetivo contribuir para o aumento da qualidade da Educação de Infância na Europa por meio do reconhecimento da importância da qualidade das relações entre famílias e educadores. O projeto se centra em quatro atividades principais: investigação sobre envolvimento parental; construção de indicadores de qualidade; identificação e partilha de boas práticas; e Jobshadowing - observação em contextos profissionais, em nível internacional, visando uma experiência em contextos diversos para generalizar as boas práticas em envolvimento parental. A finalidade última do projeto se centra na construção de uma toolbox que possa ser implementada a nível internacional (GOMES; NEVES; SILVA, 2017).

A relação família-escola tem atraído interesse de muitos pesquisadores pois, segundo Saraiva-Junges e Wagner (2016), quando bem estabelecida previne comportamentos disfuncionais. As autoras, ao perceberem lacunas na abordagem dessa temática, buscaram conhecer o estado da arte do tema "Relação Família-Escola", no Brasil, a partir de uma revisão sistemática da literatura. O levantamento revelou que os artigos refletiram a complexidade inerente à temática, assim como as metodologias disponíveis para aceder a ela, sendo que alguns deles denotaram certa dificuldade de delimitação do objeto de pesquisa. Elas concluíram que a produção acadêmica sobre o tema se encontra em momento de diagnóstico de dificuldades e constatação da necessidade de propostas de intervenção para otimização, mas que ainda não se percebem avanços quanto a proposições práticas que fomentem uma parceria efetiva entre escola e famílias.

Segundo Jacobe Loureiro (1996), a aprendizagem escolar constitui-se em um dos indicadores da capacidade ampla de aprendizagem do indivíduo, portanto, na fase escolar o desempenho é percebido pelos adultos como o principal referencial de possibilidades das crianças. As dificuldades de aprendizagem escolar e o consequente atraso, às vezes, podem ser os únicos padrões de referência que as famílias têm para avaliar seus filhos, visto que até a entrada das crianças na escola não tinham 
como obter resultados de sua aprendizagem.

Os critérios de avaliação têm uma responsabilidade muito importante, visto que expõem as expectativas de aprendizagem, considerando objetivos e conteúdos propostos para a área e para o ciclo, a organização lógica e interna dos conteúdos, as peculiaridades de cada momento na escola e as possibilidades de aprendizagem decorrentes de cada etapa do desenvolvimento cognitivo, afetivo e social em uma determinada situação. Os critérios de avaliação apontam as experiências educativas a que os alunos devem ter acesso e são consideradas essenciais para o seu desenvolvimento e socialização (BRASIL, 1997). Por vezes, quando o aluno não consegue obter um bom desempenho escolar por meio desses critérios de nota, segundo (BORUCHOVITCH; OLIVEIRA; SANTOS, 2008), ele é discriminado pela escola e pela família, o que pode exercer um impacto negativo em sua aprendizagem futura.

Foram levantadas pesquisas, no contexto nacional, que envolveram especificamente o envolvimento parental e o desempenho escolar de crianças, nas bases Scielo, Pepsic e Portal de Periódicos Capes, no período de 2009 a 2018. A primeira encontrada foi a de Cia e Barham (2009), que relacionou indicadores do envolvimento paterno com indicadores de desenvolvimento social dos filhos. Participaram 97 pares de pais e mães (com filhos na $1^{\mathrm{a}}$ ou $2^{\mathrm{a}}$ série) e 20 professoras. Para avaliar o envolvimento paterno, pais e mães responderam à Avaliação do bem-estar pessoal e familiar e do relacionamento pai-filho - Versão Paterna, e para avaliar o desenvolvimento social das crianças, os pais, as mães e as professoras preencheram o Social Skills Rating System (SSRS). Os resultados apontaram que quanto maior a frequência de comunicação entre pai e filho e de participação do pai nos cuidados e nas atividades escolares, culturais e de lazer do filho, menor o índice de hiperatividade e de problemas de comportamento e mais adequado o repertório de habilidades sociais das crianças. Os autores destacaram a provável importância do envolvimento positivo do pai no desenvolvimento social dos filhos e os prováveis benefícios de programas para promover envolvimento paterno.

Os objetivos da pesquisa de Fantinato e Cia (2011) foram comparar a frequência de envolvimento parental, entre pais e mães, e investigar a relação entre a frequência de envolvimento parental, a competência social e o desempenho escolar de crianças. Participaram do estudo 12 casais, sendo eles pais de alunos de $2^{\mathrm{a}}$ série do ensino fundamental, e três professoras dessas crianças. Os casais preencheram o questionário Avaliação do envolvimento parental e, para avaliar o repertório de habilidades sociais, os problemas de comportamento e o desempenho escolar das crianças, as professoras responderam ao Social Skills Rating System (SSRS) - Versão para professores. Os resultados mostraram que quanto maior a frequência da participação dos pais nas atividades escolares, culturais e de lazer dos filhos, maior foi o desempenho escolar das crianças. A frequência da participação das mães nas atividades escolares, culturais e de lazer dos filhos estava negativamente correlacionada com o índice de problemas de comportamento externalizantes e positivamente correlacionada com o repertório de habilidades sociais das crianças. Por fim, a comunicação entre mãe e filho estava positivamente correlacionada com o repertório de habilidades sociais das crianças.

Cia, Barham e Fontain (2012) examinaram as relações entre três formas do envolvimento paterno (a comunicação entre pai e filho; a participação do pai nos cuidados com o filho; a participação do pai nas atividades escolares, culturais e de lazer do filho) e dois aspectos do desenvolvimento infantil (autoconceito e desempenho escolar) de crianças que iniciaram as atividades escolares. Participaram 97 casais e seus filhos matriculados na $1^{\mathrm{a}}$ ou $2^{\mathrm{a}}$ série do ensino fundamental. Para avaliar o envolvimento paterno a partir de duas perspectivas diferentes, tanto os pais quanto as mães responderam à Avaliação do bem-estar pessoal e familiar e do relacionamento pai-filho - Versão Paterna. Para 
avaliar o desempenho escolar e o autoconceito, foram aplicados nas crianças o Teste de Desempenho Escolar e o Self-Description Questionnair I. Os resultados apontaram que quanto maior a frequência de comunicação entre pai e filho, a participação do pai nos cuidados com o filho e a participação do pai nas atividades escolares, culturais e de lazer do filho, maior o desempenho escolar e o autoconceito das crianças. Os autores consideraram que esses resultados foram indicativos da importância do envolvimento paterno e apontaram a necessidade de se realizarem intervenções educativas dirigidas aos homens.

Bandeira et al. (2006) avaliaram características da competência acadêmica em sua relação com o repertório de habilidades sociais e com variáveis sociodemográficas de uma amostra de 257 crianças de $1^{\mathrm{a}}$ a $4^{\mathrm{a}}$ séries do ensino fundamental. Foi aplicada a escala Social Skills Rating System (SSRS), que avalia também leitura e matemática, a 185 pais dessas crianças e 12 professores. O questionário Critério Brasil, utilizado para verificar o poder de compra das pessoas, sem a pretensão de classificar a população em termos de classes sociais, foi usado para avaliação socioeconômica. Os resultados mostraram que quanto maior a escolaridade dos pais e o nível socioeconômico dos pais, maior era a competência acadêmica dos alunos; as meninas obtiveram escores mais elevados do que os meninos em competência acadêmica; quanto maior o escore global de habilidades sociais das crianças, maior foi sua competência acadêmica e menor o número de reprovações; os alunos com melhor desempenho escolargeral apresentaram escores significativamente mais elevados de habilidades sociais do que os alunos com pior desempenho escolar geral; os melhores alunos em leitura apresentaram escores significativamente mais elevados de habilidades sociais do que os piores em leitura; os melhores alunos em matemática apresentaram escores significativamente mais elevados em habilidades sociais do que os piores em matemática; os alunos com maior estímulo dos pais apresentaram escores significativamente mais elevados de habilidades sociais do que os com pior estímulo dos pais; os alunos com maior motivação apresentaram escores significativamente mais elevados de habilidades sociais do que os alunos com pior motivação geral; os alunos com melhor funcionamento intelectual apresentaram escores significativamente mais elevados de habilidades sociais do que os alunos com pior funcionamento intelectual.

Com o objetivo de avaliar as possíveis relações entre as práticas e crenças parentais e o desempenho em escrita de alunos do ensino fundamental, Martinelli e Aguena-Matsuoka (2018) investigaram 446 alunos, que cursavam do $2^{\circ}$ ao $5^{\circ}$ ano, de ambos os gêneros e seus respectivos pais. A faixa etária dos alunos variou de 7 a 11 anos e dos pais, de 19 a 69 anos. Foram utilizados dois instrumentos, o Teste de Avaliação da Escrita (TAE) e o Inventário de Práticas e Crenças Parentais (IPCp). Os resultados revelaram uma correlação significante e positiva de intensidade fraca entre o desempenho em escrita e as crenças declaradas pelos pais.

Nomesmo sentido dessas pesquisas apresentadas, este estudo teve por objetivo principal verificar se o envolvimento parental se correlaciona com o desempenho escolar. Mais especificamente, foram delineados os seguintes objetivos secundários: verificar as médias obtidas nos instrumentos $\mathrm{e}$ no desempenho escolar; comparar as médias por escola; por ano; por idade; e por sexo.

\section{Método}

\section{Participantes}

Participaram 112 alunos do Ensino fundamental I, do $3^{\circ}(n=32), 4^{\circ}(n=38)$ e $5^{\circ}$ ano $(n=42)$. Desse total, $51(49,6 \%)$ eram do sexo masculino e 61 $(50,4 \%)$ do feminino. As idades variaram de 8 a 12 anos, com média de 9,25 e desvio padrão de 0,85 . Os estudantes eram provenientes de duas escolas públicas do Sul do Estado de Minas Gerais, sendo 40 da 1 (periférica), e 72 da escola 2 (central). 


\section{Instrumentos}

Avaliação do Relacionamento com o Pai (CIA; BARHAM; FONTAINE, 2012).

É um questionário estruturado em seis tópicos divididos em: relacionamento do pai e a criança quanto a aspectos gerais; o relacionamento da criança e seu pai quanto a aspectos gerais; os próximos tópicos estão relacionados ao pai para a criança: em relação às atividades escolares; às atividades da vida diária; às atividades de lazer e recreativas e; em relação aos contatos sociais. Seguem exemplos de questões:

Quadro 1 - Avaliação do relacionamento com o Pai

\begin{tabular}{lccccc}
\hline & $\begin{array}{c}\text { Uma vez } \\
\text { por dia } \\
(4)\end{array}$ & $\begin{array}{c}\text { Duas ou três } \\
\text { vezes por } \\
\text { semana }(3)\end{array}$ & $\begin{array}{c}\text { Uma vez } \\
\text { por semana } \\
(2)\end{array}$ & $\begin{array}{c}\text { Uma vez } \\
\text { por mês } \\
(1)\end{array}$ & $\begin{array}{c}\text { Nunca } \\
(0)\end{array}$ \\
\hline Seu pai... & & & & & \\
\hline Em relação às atividades escolares & & & & \\
\hline a- Acompanha o seu progresso escolar? & & & & \\
\hline b- Auxilia você nas lições de casa? & & & & \\
\hline c- Valoriza as suas conquistas acadêmicas?
\end{tabular}

Fonte: Dados da pesquisa.

Avaliação do Relacionamento com a Mãe (CIA; BARHAM; FONTAINE, 2012)

É um questionário estruturado em seis tópicos, igual ao anterior, divididos em: relacionamento da mãe e a criança quanto a aspectos gerais; o relacionamento da criança e sua mãe quanto a aspectos gerais; os próximos tópicos estão relacionados à mãe para a criança: em relação às atividades escolares; às atividades da vida diária; às atividades de lazer e recreativas e; em relação aos contatos sociais.

Esses questionários apresentam uma escala Likert, na qual o respondente terá que assinalar a frequência em que o fato acontece, nesse sentido as colunas das frequências são identificadas como: Uma vez por dia; Duas ou três vezes por semana; Uma vez por semana; Uma vez por mês e; Nunca.

Os escores estão assim distribuídos: uma vez por dia, vale 4 pontos; duas ou três vezes por semana 3 pontos; uma vez por semana 2 pontos; uma vez por mês 1 ponto e; nunca zero. $\mathrm{O}$ escore pode variar de
0 a 164 pontos, sendo que quanto maior o escore, maior a atenção dos pais.

Desempenho escolar (DA) - Notas das secretarias das escolas

Foram coletadas as notas, do último bimestre do primeiro semestre de 2015 , de todas as disciplinas, a saber, português, matemática, geografia, história, ciências, inglês, informática, arte, ética e literatura. Foi calculada a média geral das notas dos alunos para as análises, sendo que o intervalo poderia variar de 0 a 20 pontos, que é o parâmetro da Superintendência de Ensino da cidade onde se situam as escolas pesquisadas.

O sistema de atribuição de notas de uma das escolas públicas era feito por meio de letras, de A a D. No entanto, a própria secretária da escola fez a conversão dessas letras em conceitos de 0 a 20 por meio de uma tabela que é utilizada pela escola para atender à Superintendência de Ensino, no caso de transferência de alunos para escolas que atribuem as notas de acordo com esse parâmetro estipulado. 


\section{Procedimentos}

Inicialmente foi solicitada à Superintendência de Ensino da cidade a autorização para coleta de dados e foram indicadas duas escolas públicas. Posteriormente o projeto foi submetido ao Comitê de Ética de Pesquisas, cujo número do parecer é 38363014.4.0000.5102.

Os pesquisadores contataram as escolas indicadas para explicar os objetivos e procedimentos da pesquisa e solicitaram às professoras que entregassem os Termos de Consentimento Livre e Esclarecido para as crianças para obterem as assinaturas de seus pais ou responsáveis. Nas datas estipuladas para a coleta dos dados, os pesquisadores verificaram quais os alunos que tinham aprovação para participar da pesquisa. Em seguida, foi solicitado que os alunos assinassem o Termo de Assentimento. Para os que assinaram foi iniciada a coleta, coletivamente, em sala de aula, em espaço cedido pelos professores, em uma só sessão, na seguinte ordem: 1) Relacionamento com o Pai na Visão dos Filhos 2) Relacionamento com a Mãe na Visão dos Filhos.

Cabe informar que os questionários foram lidos, pergunta a pergunta pelos pesquisadores e as crianças foram respondendo todas de uma só vez, visto que se percebeu que os alunos tiveram dúvidas quanto aos termos utilizados nos instrumentos e tinham dificuldades para ler. Assim esse procedimento permitiu ir esclarecendo as dúvidas enquanto as crianças iam respondendo. O tempo de aplicação foi de $1 \mathrm{~h}$.

Procedimentos de análise dos dados

Para as análises estatísticas dos dados quantitativos utilizou-se o programa estatístico Statistical Package for the Social Sciences- SPSS 22, um pacote estatístico para análise de estudos em ciências sociais. As análises estatísticas utilizadas foram as descritivas e a inferenciais, estas por meio do Test $t$ de Student para comparação de dois grupos e a Análise da Variância - ANOVA - para três ou mais grupos. Foi também usada a Correlação de Pearson. O nível de significância adotado para todas as análises foi de $p \leq 0,05$.

\section{Resultados}

O primeiro objetivo secundário foi $\mathrm{o}$ de verificar as médias das respostas aos questionários de relacionamento com os pais e as mães e o desempenho escolar. Como os números de itens eram diferentes para cada tópico dos questionários, a média foi ponderada pela quantidade de itens, assim a pontuação poderia ir de 0 a 4 para cada tópico e como o questionário tem seis tópicos, o total poderia variar de 0 a 24 . A Tabela 1 apresenta esses resultados. 
Tabela 1 - Estatísticas descritivas do relacionamento com os pais e desempenho escolar

\begin{tabular}{lcccc}
\hline & Média & Desvio Padrão & Mínimo & Máximo \\
\hline Relacionamentos gerais com o pai & 2,46 & 1,17 & 0 & 4 \\
Relacionamentos gerais da criança com o pai & 2,59 & 1,13 & 0 & 4 \\
Atividades escolares & 2,37 & 1,39 & 0 & 4 \\
Atividades da vida diária & 1,75 & 1,30 & 0 & 4 \\
Atividades de lazer e recreativas & 2,46 & 1,29 & 0 & 4 \\
Contatos sociais & 2,50 & 1,51 & 0 & 4 \\
Total Relacionamento com o pai & 14,11 & 6,62 & 0 & 24 \\
Relacionamentos gerais com a mãe & 3,14 & 0,82 & 0 & 4 \\
Relacionamentos gerais da criança com a mãe & 3,10 & 0,74 & 0 & 4 \\
Atividades escolares - mãe & 3,01 & 0,93 & 0 & 4 \\
Atividades da vida diária - mãe & 2,47 & 1,08 & 0 & 4 \\
Atividades de lazer e recreativas - mãe & 2,91 & 1,08 & 0 & 4 \\
Contatos sociais - mãe & 2,96 & 1,20 & 0 & 4 \\
Total Relacionamento com a mãe & 17,60 & 4,29 & 3 & 24 \\
Desempenho escolar & 14,46 & 3,24 & 7 & 20 \\
\hline
\end{tabular}

Fonte: Dados da pesquisa.

Verifica-se, na Tabela 1, que todas as médias dos tópicos dos questionários quanto ao relacionamento com a mãe foram superiores às médias com o pai. As médias mais baixas nos relacionamentos foi para as "Atividades da vida diária" com o pai $(\mathrm{M}=1,75)$ e com a mãe $(2,47)$.

A média mais alta para o relacionamento com o pai foi para os "Relacionamentos gerais da criança com o pai" $(\mathrm{M}=2,59)$. Para o relacionamento com a mãe, a média mais alta foi para "Relacionamentos gerais com a mãe". Observa-se, ainda, que as pontuações para os totais ficaram acima da metade dos pontos que poderiam ser atingidos, no entanto, a média do relacionamento com o pai ficou em apenas $58,79 \%$ do escore máximo. Já para o relacionamento com a mãe essa porcentagem foi de $73,33 \%$.
Quanto às pontuações mínimas e máximas, observa-se que tanto para o relacionamento com o pai como para a mãe os totais foram alcançados - 24 pontos. Em relação ao Desempenho escolar, cabe lembrar que poderia variar de 0 a 20 , assim a média de 14,46 está acima da metade dos pontos que poderiam ser alcançados e houve crianças que alcançaram o escore máximo.

Os próximos objetivos secundários foram os de comparar as médias obtidas por escola; por ano; por idade; e por sexo. As comparações por escola, por ano e por idade não geraram índices estatisticamente significativos nem pelos tópicos, nem pelo total das médias obtidas nos questionários e no desempenho escolar. Somente para o sexo houve índices estatisticamente significativos, como pode ser observado na Tabela 2 . 
Tabela 2 - Comparação entre as médias por sexo pelo Test t de Student

\begin{tabular}{|c|c|c|c|c|c|c|}
\hline & Sexo & $\mathrm{N}$ & M & Desvio Padrão & $t$ & $p$ \\
\hline \multirow[t]{2}{*}{ Desempenho escolar } & Masculino & 51 & 13,69 & 3,33 & $-2,340$ & $p \leq 0,05$ \\
\hline & Feminino & 61 & 15,10 & 3,04 & & \\
\hline \multirow[t]{2}{*}{ Relacionamentos gerais com o pai } & Masculino & 51 & 2,13 & 1,28 & $-2,759$ & $p \leq 0,05$ \\
\hline & Feminino & 61 & 2,73 & 1,01 & & \\
\hline \multirow[t]{2}{*}{ Relacionamentos gerais da criança com o pai } & Masculino & 51 & 2,26 & 1,23 & $-2,870$ & $p \leq 0,05$ \\
\hline & Feminino & 61 & 2,86 & 0,98 & & \\
\hline \multirow[t]{2}{*}{ Atividades escolares } & Masculino & 51 & 2,04 & 1,38 & $-2,283$ & $p \leq 0,05$ \\
\hline & Feminino & 61 & 2,64 & 1,35 & & \\
\hline \multirow[t]{2}{*}{ Atividades da vida diária } & Masculino & 51 & 1,43 & 1,31 & $-2,412$ & $p \leq 0,05$ \\
\hline & Feminino & 61 & 2,02 & 1,24 & & \\
\hline \multirow[t]{2}{*}{ Atividades de lazer e recreativas } & Masculino & 51 & 2,05 & 1,36 & $-3,150$ & $p \leq 0,05$ \\
\hline & Feminino & 61 & 2,80 & 1,14 & & \\
\hline \multirow[t]{2}{*}{ Contatos sociais } & Masculino & 51 & 2,17 & 1,59 & $-2,132$ & $p \leq 0,05$ \\
\hline & Feminino & 61 & 2,77 & 1,40 & & \\
\hline \multirow[t]{2}{*}{ Total Relacionamento com o pai } & Masculino & 51 & 12,08 & 7,12 & $-3,074$ & $p \leq 0,05$ \\
\hline & Feminino & 61 & 15,81 & 5,70 & & \\
\hline \multirow[t]{2}{*}{ Relacionamentos gerais com a mãe } & Masculino & 51 & 3,07 & 0,85 & $-0,815$ & 0,417 \\
\hline & Feminino & 61 & 3,20 & 0,79 & & \\
\hline \multirow[t]{2}{*}{ Relacionamentos gerais da criança com a mãe } & Masculino & 51 & 2,93 & 0,82 & $-2,191$ & $\mathrm{p} \leq 0,05$ \\
\hline & Feminino & 61 & 3,24 & 0,65 & & \\
\hline \multirow[t]{2}{*}{ Atividades escolares - mãe } & Masculino & 51 & 2,84 & 0,95 & $-1,862$ & 0,065 \\
\hline & Feminino & 61 & 3,16 & 0,90 & & \\
\hline \multirow[t]{2}{*}{ Atividades da vida diária - mãe } & Masculino & 51 & 2,15 & 1,06 & $-2,976$ & $\mathrm{p} \leq 0,05$ \\
\hline & Feminino & 61 & 2,74 & 1,03 & & \\
\hline \multirow[t]{2}{*}{ Atividades de lazer e recreativas - mãe } & Masculino & 51 & 2,58 & 1,10 & $-3,008$ & $\mathrm{p} \leq 0,05$ \\
\hline & Feminino & 61 & 3,18 & 0,98 & & \\
\hline \multirow[t]{2}{*}{ Contatos sociais - mãe } & Masculino & 51 & 2,81 & 1,20 & $-1,209$ & 0,229 \\
\hline & Feminino & 61 & 3,09 & 1,20 & & \\
\hline \multirow[t]{2}{*}{ Total Relacionamento com a mãe } & Masculino & 51 & 16,39 & 4,37 & $-2,814$ & $\mathrm{p} \leq 0,05$ \\
\hline & Feminino & 61 & 18,61 & 3,97 & & \\
\hline
\end{tabular}

Fonte: Dados da pesquisa.

Verifica-se, na Tabela 2, que somente para os tópicos "Relacionamentos gerais com a mãe", "Relacionamentos gerais da criança com a mãe" e "Contatos sociais - mãe" não houve diferenças estatisticamente significativas. No entanto, as médias das meninas foram maiores em todos os tópicos, nos totais dos questionários e no desempenho escolar. Inversamente, os desvio-padrão para os meninos foram maiores em todos os casos, evidenciando a maior dispersão de suas respostas.

Em seguida foram correlacionados os tópicos e totais dos questionários com o Desempenho escolar, que era o objetivo principal desta pesquisa. Os resultados apontaram que não há correlação entre essas variáveis. 


\section{Discussão}

De acordo com os objetivos secundários desta pesquisa, foram verificados o envolvimento com o pai e com a mãe na visão do filho e o desempenho escolar. A média alcançada no questionário “Avaliação do relacionamento com o pai”, de 14,11, ficou acima da metade do escore total, equivalente a 24 pontos. Os resultados apontaram que 10 crianças zeraram no instrumento. Foi solicitado pelos pesquisadores que essas crianças explicassem no instrumento a razão de não terem preenchido nada e foram indicadas como causas o falecimento do pai ou a não participação do pai no meio familiar, ou ainda, que nunca conheceram o pai. Esse fato pode explicar o desvio padrão alto em relação às médias das crianças nesse instrumento de 6,62.

Percebeu-se também que em todos os tópicos as médias do relacionamento com o pai foram menores que no relacionamento com a mãe. Martinelli (2002) destacou que um fator a ser observado no processo de aprendizagem é o aspecto afetivo, e que um ambiente contraditório da manifestação afetiva de atenção e a depreciação infantil interferem negativamente no processo de aprendizagem das crianças. Cia e Barham (2009) destacam o papel do pai, alegando que sua total ausência é um fator de risco ao desenvolvimento das crianças porque o envolvimento do pai afeta o compromisso dos seus filhos nos estudos, impactando no seu desempenho escolar.

Cia e Barham (2009) encontraram em sua pesquisa que quanto maior era a frequência de comunicação entre pai e filho e de participação do pai nos cuidados e nas atividades escolares, culturais e de lazer do filho, menor o índice de hiperatividade e de problemas de comportamento e mais adequado era o repertório de habilidades sociais das crianças. As pesquisadoras destacaram a importância do envolvimento positivo do pai no desenvolvimento social dos filhos e os prováveis benefícios de programas para promover envolvimento paterno. Cia, Barham e Fontain (2012) encontraram também, além desses resultados, a melhora no autoconceito das crianças que tinham envolvimento paterno.

Para o instrumento "Avaliação do relacionamento com a mãe" a média foi de 17,60 pontos, em um intervalo que poderia variar de 0 a 24 pontos. Essa média ficou 7,60 pontos acima da metade da pontuação - 10 pontos - e $24,73 \%$ maior que a média do relacionamento com o pai. No estudo de Fantinato e Cia (2011) ficou evidenciado que a frequência da participação das mães nas atividades escolares, culturais e de lazer dos filhos estava negativamente correlacionada com o índice de problemas de comportamento externalizantes e positivamente correlacionada com o repertório de habilidades sociais das crianças.

As médias mais baixas em ambos os relacionamentos foi para o tópico "Atividades da vida diária". Nele havia perguntas como: "Incentiva você a realizar atividades domésticas (cuidar das próprias coisas, da casa etc.)?" e "Auxilia você nas atividades de higiene (escovar os dentes, tomar banho)? Essas médias mais baixas parecem indicar que, devido à idade, os pais não tenham mais atenção quanto a esses cuidados com seus filhos ou talvez sejam atividades tão corriqueiras que não são levadas em consideração pelas crianças.

O Desempenho escolar das crianças investigado neste estudo ficou acima da metade da pontuação máxima, com média de 14,46, em um intervalo da pontuação poderia variar de 0 a 20. Estudos citados anteriormente indicaram que à medida que a criança consegue atender às tarefas escolares, exercendo o papel de aluno, aplicando-se nas avaliações, melhora o seu desempenho escolar. Em decorrência disso, é despertada a autoestima e a autoconfiança, fatores que auxiliam na capacidade de superar os desafios do dia a dia, tanto no ambiente escolar ou no extraescolar, contribuindo para a busca do aprender por si só. Geralmente, entre as crianças que têm o melhor desempenho na escola, se encontram as de famílias que se envolvem mais nos estudos dos seus filhos que, na maioria das vezes, dispõem 
de recursos econômicos e/ou afetivos, elementos entendidos como essenciais (CASARIN; RAMOS, 2007; GUIDETTI et al., 2010; LIMA; MACHADO, 2012).

Cabe lembrar que o desempenho escolar se constitui em um dos indicadores da capacidade ampla de aprendizagem do indivíduo, portanto, na fase escolar o desempenho é percebido pelos adultos como o principal referencial de possibilidades das crianças. Às vezes, as dificuldades de aprendizagem e o consequente atraso escolar são os únicos padrões de referência que as famílias têm para avaliar seus filhos (JACOB; LOUREIRO, 1996). Nesse sentido, cabe à escola ficar atenta quanto a esses problemas, visto que, quando o aluno não consegue obter um bom desempenho escolar, ele é discriminado pela escola e pela família, o que pode exercer um impacto negativo em sua aprendizagem futura (BORUCHOVITCH; OLIVEIRA; SANTOS, 2008).

Quanto aos objetivos secundários, de comparar as médias obtidas pelos participantes por escola, ano escolar e idade, não foram encontradas diferenças estatisticamente significativas, indicando que se deveram ao acaso e evidenciando que as respostas das crianças não sofreram alterações quanto a estes critérios. Assim, na amostra estudada, o fato de pertencer a uma escola central ou periférica, a anos escolares distintos ou de ter idades entre 8 e 12 anos não incitou distinções na percepção do relacionamento com os pais por parte dos alunos. Contava-se com certo amadurecimento que pudesse influenciar na percepção das crianças por causa da evolução nos anos escolares e da idade dos participantes, embora não tenha sido encontrada na literatura pesquisada estudos que tivessem investigado essas variáveis.

A diferença das médias pelo sexo foi a única que teve índices estatisticamente significativos para quase todos os tópicos dos questionários do relacionamento com os pais e seus totais e o desempenho escolar. Somente para os tópicos "Relacionamentos gerais com a mãe", "Relacionamentos gerais da criança com a mãe" e "Contatos sociais - mãe" não houve diferenças estatisticamente significativas. Esses resultados evidenciam que esses relacionamentos mais gerais não são percebidos pelos meninos e meninas com disparidade, porque são mais cotidianos. Exemplos de perguntas para o tópico "Relacionamentos gerais com a mãe" são: "Pergunta aspectos do dia a dia" e "Pergunta sobre seus amigos". Para o tópico "Relacionamentos gerais da criança com a mãe", são exemplos de perguntas: "Faz elogios a sua mãe" e "Desafia as regras ou desobedece".

Esse cotidiano mais geral, no qual não há diferenças significativas na percepção das crianças em relação ao relacionamento com suas mães vão ao encontro dos resultados da pesquisa de Borsa e Nunes (2011), na qual os artigos levantados sobre maternidade e paternidade reforçaram a ideia construída socialmente de que as crianças devem ser cuidadas principalmente pelas mães, concepção construída ao longo da história que acaba por diferenciar o papel de homens e mulheres na família e a maneira com que pais e mães se relacionam com suas crianças.

Quanto ao tópico "Contatos sociais - mãe", que também não teve diferenças estatisticamente significativas entre as médias dos meninos e meninas, as perguntas eram somente duas: "Incentiva contato com outras crianças" e "Incentiva contato com outros adultos”. Esses questionamentos, provavelmente por sua generalidade, não tenham sido percebidos de maneira diferente entre os sexos ou não tenham sido alvo de maior atenção quanto a esta variável.

Cabe lembrar que as médias das meninas foram maiores para todas variáveis e que os meninos tiveram mais dispersão nas respostas em relação à média. Bandeira et al. (2006) também encontraram melhores resultados para as meninas no desempenho escolar. Todos esses achados em relação à diferença por sexo podem evidenciar que as meninas sejam mais sensíveis para perceberem as interações com os 
pais e/ou que os meninos não tenham tanta percepção em relação a elas ou simplesmente não dirigem tanta atenção aos detalhes desses relacionamentos.

Finalmente, quanto ao objetivo principal, fato de não ter havido correlação entre a avaliação do relacionamento com os pais e o desempenho escolar na amostra pesquisada vai de encontro aos resultados das pesquisas de Cia e Barham (2009), Fantinato e Cia (2011) e Martinelli e Aguena-Matsuoka (2018). Chama a atenção que mesmo o tópico relacionado às atividades escolares não tenha se correlacionado ao desempenho escolar. Essa pode ser, então, uma característica da amostra pesquisada em não vincular essas variáveis ou, ainda, pode evidenciar que não haja o devido envolvimento parental e que as escolas não se atentem para o fato. Por isso que, dada a importância dessa relação, o Programa Erasmus + da Comissão Europeia se centra na investigação sobre envolvimento parental, na construção de indicadores de qualidade, na identificação e partilha de boas práticas e na observação em contextos profissionais, em nível internacional, visando uma experiência em contextos diversos para generalizar as boas práticas em envolvimento parental (GOMES; NEVES; SILVA, 2017).

\section{Considerações Finais}

Os resultados encontrados neste trabalho não indicaram correlações entre as médias dos alunos com relação ao relacionamento com o pai e com a mãe e o desempenho escolar, embora o levantamento teórico e de pesquisas tenha indicado o contrário. Também não foram encontradas diferenças nas médias das crianças para as variáveis, escola, ano escolar e idade. No entanto, houve diferenças estatisticamente significativas quanto às médias pelo sexo dos participantes, com pontuações mais altas para as meninas. Outros estudos já obtiveram resultados semelhantes quanto ao desempenho escolar, mas outras pesquisas poderiam verificar se a pontuação mais alta das meninas é uma tendência de elas perceberem o relacionamento com os pais de maneira mais positiva ou serem mais resilientes.

A família e a escola compartilham a responsabilidade pelo desenvolvimento cognitivo infantil. Da parte da família percebe-se que, atualmente, a maioria dos pais trabalha fora e tem pouco tempo disponível para a vida doméstica e para a atenção com os filhos. Nesse sentido, nota-se que, as famílias têm delegado essa tarefa para a escola, transferindo parte dessa responsabilidade pela construção do conhecimento dos filhos. Diante dos resultados deste estudo, na contramão dos outros, é preciso refletir se eles estão indicando que essas duas instituições não têm agido em conjunto, no sentido de esta relação estar refletindo na percepção das crianças.

Nessa direção, as escolas poderiam investir no fortalecimento do conselho escolar, das associações de pais e mestres, abrindo espaço para a participação dos pais, para promover a articulação da família com a escola e com a comunidade. A inclusão de programas de apoio aos pais poderia ser uma estratégia utilizada para ajudar os pais e responsáveis a acompanhar as atividades de aprendizagem escolar dos filhos.

É importante ressaltar que o desempenho escolar é considerado como a indicação quantitativa da evolução do aluno, mas na verdade é um contexto maior que norteia esta avaliação, indo além do conhecimento intelectual. Portanto, na formação do caráter de uma criança todos que de uma forma geral tenham participação na sua vida devem trabalhar de forma conjunta, formando um indivíduo mais preparado e com capacidade para viver em sociedade.

Dentre as limitações desta pesquisa pode-se citar a amostra reduzida e de somente duas escolas municipais. No entanto, essa indicação foi feita pela Secretária da Educação. Outra limitação foi a redução do tempo de coleta dos dados, pois os dois questionários tiveram que ser aplicados de uma só vez, visto que os professores não disponibilizaram mais tempo. 
Outras pesquisas poderiam ser desenvolvidas explorando variáveis que não foram foco deste estudo, como a inclusão de uma pergunta quanto à configuração da família da criança, visto que atualmente são muitas as formas de constituição das famílias. Além disso, poderiam ser compostas amostras mais ilustrativas, por exemplo com alunos de escolas particulares.

No entanto, um fato que merece destaque neste trabalho foi é quanto à escassez de literatura que contemple as duas variáveis investigadas ao mesmo tempo, o relacionamento com a família e o desempenho escolar, no contexto brasileiro. Vale salientar que embora não tenha sido encontrada uma correlação entre essas variáveis neste estudo, outras pesquisas apontam essa associação. Também é notório que a escola anseia por um envolvimento maior dos pais na vida escolar de seus filhos, o que aponta para a necessidade de mais pesquisas que possam proporcionar articulações psicoeducacionais entre esses dois grupos tão importantes no desenvolvimento das crianças.

\section{Referências}

BANDEIRA, M.; ROCHA, S. S.; PIRES, L. G.; DEL PRETTE, Z. A. P.; DEL PRETTE, A. Competência acadêmica de crianças do ensino fundamental: características sociodemográficas e relação com habilidades sociais. Interação em Psicologia, Curitiba, v. 10, n. 1, p. 53-62, 2006. Disponível em: http:// ojs.c3sl.ufpr.br/ojs/index.php/psicologia/article/ viewFile/5773/4209. Acesso em: 15 set. 2018.

BORSA, J. C.; NUNES, M. L. T. Aspectos psicossociais da parentalidade: o papel de homens e mulheres na família nuclear. Psicologia Argumento, Curitiba, v. 29, n. 64, p. 31-39, 2011. Disponível em: https://periodicos. pucpr.br/index.php/psicologiaargumento/article/ view/19835/19141. Acesso em: 15 set. 2018.

BORUCHOVITCH, E.; OLIVEIRA, K. L.; SANTOS, A. A. A. Leitura e desempenho escolar em português e matemática no ensino fundamental. Paidéia, Ribeirão Preto, v. 18, n. 41, p. 531-540, set./dez. 2008. Disponível em: $\quad$ http://www.scielo.br/scielo.php?script=sci arttext\&pid=S0103-863X2008000300009. Acesso em: 15 set. 2018.
BRASIL. Secretaria da Educação Fundamental. Parâmetros curriculares nacionais: introdução aos parâmetros curriculares nacionais. Brasília, DF: MEC/SEF, 1997. Disponível em: http://portal.mec.gov.br/seb/arquivos/pdf/ livro01.pdf. Acesso em: 15 set. 2018.

BRONFENBRENNER, U. La ecología del desarrollo humano: experimentos en entornos naturales y diseñados. Barcelona: Editorial Paidós, 2002.

CASARIN, N. E. F.; RAMOS, M. B. J. Família e aprendizagem escolar. Revista de Psicopedagogia, São Paulo, v. 24, n. 74. p. 82-201, 2007. Disponível em: http:// pepsic.bvsalud.org/pdf/psicoped/v24n74/v24n74a09. pdf. Acesso em: 15 set. 2018.

CHRISTOVAM, A. C. C.; CIA, F. O envolvimento parental na visão de pais e professores de alunos com necessidades educacionais especiais. Revista Brasileira de Educação Especial, Marília, v. 19, n. 4, p. 563-582, out./dez. 2013. Disponível em: http:// www.scielo.br/scielo.php?script=sci_arttext\&pid $=$ S1413-65382013000400007. Acesso em: 15 set. 2018 .

CIA, F.; BARHAM, E. J. O envolvimento paterno e o desenvolvimento social de crianças. Psicologia em Estudo, Maringá, v. 14, n. 1, p. 67-74, 2009. Disponível em: http://www.scielo.br/pdf/pe/v14n1/a09v14n1.pdf. Acesso em: 15 set. 2018.

CIA, F.; BARHAM, E. J.; FONTAINE, A. M. G. V. Desempenho escolar e autoconceito de escolares: contribuições do envolvimento paterno. Estudos de Psicologia, Campinas, v. 29, n. 4, p. 461-470, 2012. Disponível em: http://www.scielo.br/pdf/estpsi/v29n4/ v29n4a01.pdf. Acesso em: 15 set. 2018.

FANTINATO, A. C.; CIA, F. Envolvimento parental, competência social e o desempenho escolar de escolares. Psicologia Argumento, Curitiba, v. 29, n. 67, p. 499511, 2011. Disponível em: http://132.248.9.34/hevila/ Psicologiaargumento/2011/vol29/no67/9.pdf. Acesso em: 28 mar. 2015.

GOMES, P. G.; NEVES, I.; SILVA, B. Qualidade na educação de infância através do envolvimento parental - Projeto EQuaP. Revista de Estudios e Investigación en Psicología y Educación, Coruña, n. 5, 2017. Disponível em: http://revistas.udc.es/index.php/reipe/article/view/ reipe.2017.0.05.2675/pdf. Acesso em: 15 set. 2018.

GUIDETTI, A. A.; LIMA, F. F.; BARTHOLOMEU, D.; MONTIEL, J. M.; MACHADO, A. A. Estilos parentais e dificuldades de aprendizagem na escrita: análise de suas correlações. In: CAPOVILLA F. (org.). Transtornos de aprendizagem: progressos em avaliação e intervenção preventiva e remediativa. São Paulo: Memnon, 2010. p. 141-149. 
JACOB, A. V; LOUREIRO, S. R. Desenvolvimento afetivo - o processo de aprendizagem e o atraso escolar. Paidéia, Ribeirão Preto, n. 10/11, p. 149-160, fev./ago. 1996. Disponível em: http://www.scielo.br/pdf/paideia/ n10-11/11.pdf. Acesso em: 15 set. 2018.

LIMA, A. M.; MACHADO, L. B. O "bom aluno" nas representações sociais de professoras: o impacto da dimensão familiar. Revista Psicologia \& Sociedade, Belo Horizonte, MG, v. 24, n. 1, p. 150-159, 2012. Disponível em: http://www.scielo.br/scielo.php?script $=$ sci_arttext $\&$ pid $=$ S0102-71822012000100017. Acesso em: 15 set. 2018.

MARTINELLI, S.C. Os aspectos afetivos das dificuldades de aprendizagem. In: SISTO, F. F.; BORUCHOVITCH, E.; FINI, L. D. T.; BRENELLI, R. P.; MARTINELLI, S. C. (org.). Dificuldades de aprendizagem no contexto psicopedagógico. 2.ed. Petrópolis: Editora Vozes, 2002, p. 190-213.
MARTINELLI, S. C.; AGUENA-MATSUOKA, E. C. Um estudo sobre práticas e crenças parentais e o desempenho em escrita de crianças. Educar em Revista, Curitiba, v. 34, n. 69, p. 261-276, 2018. Disponível em: https://revistas.ufpr.br/educar/article/view/54291/35478. Acesso em: 15 set. 2018.

SARAIVA-JUNGES, L. A.; WAGNER A. Os estudos sobre a relação família-escola no Brasil: uma revisão sistemática. Educação, Porto Alegre, v. 39, n. esp., p. 114-124, 2016. Disponível em: http://www.redalyc.org/ pdf/848/84850103013.pdf. Acesso em: 15 set. 2018.

SMITH, C.; STRICK, L. Dificuldades de aprendizagem de $A$ - Z: guia completo para educadores e pais. São Paulo: Penso, 2012.

Recebido em: 16 jul. 2019

Aceito em: 8 out. 2019 